УДК 661.183.2,620.181.4

\title{
ИЗУЧЕНИЕ СВОЙСТВ АКТИВНЫХ УГЛЕЙ, ПОЛУЧЕННЫХ ИЗ СУХИХ ШИШЕК СОСНЫ ОБЫКНОВЕННОЙ
}

\author{
() Ш.К. Амерханова", А.С. Уали, Р.К. Жаслан
}

\author{
Карагандинский государственный университет им. Е.А. Букетова, \\ ул. Университетская, 28, Караганда, 100028 (Казахстан), \\ e-mail: amerkhanova_sh@mail.ru
}

Исследовано получение активных углей из отходов хвойной древесины (сосны обыкновенной (Pínus sylvéstris)) путем модифицирования ортофосфорной кислотой и с последующей карбонизацией при $800{ }^{\circ} \mathrm{C}$ и высокотемпературной обработкой водяным паром. Изучены сорбционных свойств полученного материала по отношению к ионам меди (II). Исследованы структурные особенности продуктов, полученных в процессе карбонизации. Показано, что в процессе карбонизации образцов с добавками $\mathrm{H}_{3} \mathrm{PO}_{4}$ при температуре $800{ }^{\circ} \mathrm{C}$ образуется пористый материал с удельной поверхностью до $870 \mathrm{~m}^{2} /$ г. Установлено, что сорбционная емкость по йоду сорбента, карбонизированного при $800{ }^{\circ} \mathrm{C}$, составляет 128,68\%. Также показано, что полученные активные угли могут применяться при очистке вод от ионов меди (II). Кинетика этого процесса описывается моделью псевдопервого порядка, сорбции предшествует диффузия.

Ключевые слова: сосновые шишки, ортофосфорная кислота, сорбционная емкость по йоду, ионы меди (II).

\section{введение}

Опасность загрязнения окружающей среды тяжелыми металлами, радиоактивными элементами диктует необходимость создания недорогих сорбентов на основе возобновляемого растительного сырья при минимальном числе технологических стадий процесса. Анализ литературных данных показал, что за последнее десятилетие резко возросло число публикаций, посвященных исследованию свойств сорбентов, полученных на основе лесохимического сырья [1].

Целью настоящей работы являлось получение активных углей из отходов хвойной древесины (сосны обыкновенной (Pínus sylvéstris)) путем модификации ортофосфорной кислотой с последующей карбонизацией при $800{ }^{\circ} \mathrm{C}$ и высокотемпературной обработкой водяным паром, а также изучение сорбционных свойств полученного материала по отношению к ионам меди (II).

\section{Экспериментальная часть}

В качестве исходного сырья использовали измельченную массу (0,5-2 мм), полученную на основе сухих остатков (шишек) хвойной древесины, влажность которого составляла 8\% [2], содержание летучих веществ $-12,2 \%$ [3].

Модифицирование исходного сырья проводили путем его пропитки модификатором с последующим постоянным перемешиванием при температуре $70{ }^{\circ} \mathrm{C}$. Массовое соотношение сырья к модификатору было $1: 5$. В качестве модификатора был использован раствор ортофосфорной кислоты (10 моль/л). Выпаривание вели до образования влажного остатка. Температурную обработку - при температурах 200,

Амерханова Шамшия - профессор кафедры физической и аналитической химии, доктор химических наук, професcop, e-mail: amerkhanova_sh@mail.ru Уали Айтолкын - доцент кафедры химической технологии и нефтехимии, кандидат химических наук, e-mail: ualieva.84@mail.ru

Жаслан Рымгуль - студент кафедры физической и аналитической химии, e-mail: rima93@list.ru $300,400,500,600,700,800^{\circ} \mathrm{C}$, со скоростью повышения температуры $10{ }^{\circ} \mathrm{C} /$ мин и выдержкой при конечной температуре 60 мин. После термообработки полученный карбонизированный материал промывали дистиллированной водой (3 раза), высушивали при температуре $105^{\circ} \mathrm{C}$.

\footnotetext{
* Автор, с которым следует вести переписку.
} 
Исследование пористой структуры и удельной поверхности проводили на газоадсорбционном анализаторе TriStar II. ИК-Фурье-спектроскопический анализ образцов был проведен на приборе ФСМ 1201.

Дериватографический анализ осуществляли на приборе Дериватограф-1000.

Определение сорбционной емкости по йоду проводили по методике [4]. Сорбцию по отношению к ионам меди (II) - в статических условиях по методике [5], в основу эксперимента был положен метод планирования эксперимента [6].

\section{Обсуждение результатов}

Исследование пористой структуры и удельной поверхности сорбента, карбонизированного при

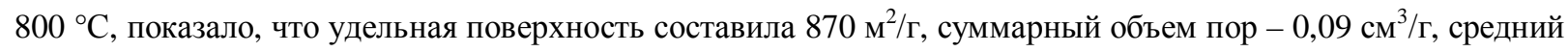
размер пор - 3,7 нм. Следовательно, исследуемый сорбент можно отнести к мезопористым.

В ИК-Фурье-спектрах модифицированного сорбента зафиксированы полосы поглощения при 1085,

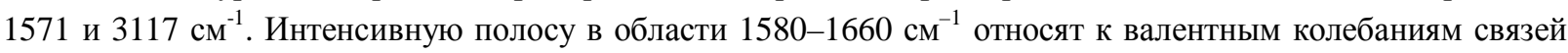
$\mathrm{C}=\mathrm{C}$ ароматических циклов, хотя в этой области в некоторых случаях могут поглощать и олефиновые $\mathrm{C}=\mathrm{C}$ связи, входящие в линейную систему сопряжения. Пик поглощения при $3117 \mathrm{~cm}^{-1}$ можно отнести к валентным колебаниям ароматических С-Н-связей. Поглощение в области $1085 \mathrm{~cm}^{-1}$ показывает наличие на поверхности сорбента неорганических ионов $\mathrm{PO}_{4}{ }^{2-}, \mathrm{HPO}_{4}{ }^{-}$, что свидетельствует о прохождении процесса модификации сорбента фосфат-ионами (рис. 1).

Далее был проведен термографический анализ модицированного сорбента, на рисунке 2 приведена термограмма разложения сорбента.

Известно, что основную часть массы древесины составляет целлюлоза и лигнин, в связи с этим при исследовании деструкции древесного сорбента целлюлоза рассматривается как модельный объект.

Карбонизация целлюлозы протекает в 4 основные стадии [7]. В ходе первой стадии в интервале температур 25-150 들 происходит преимущественно процесс выделения адсорбированной воды с поверхностных слоев, а также возможно возникновение дегидратации за счет образования воды из гидроксильных и водородных групп. Потеря массы составляет $\approx 5 \%$.

Вторая стадия протекает в интервале температур $150-240{ }^{\circ} \mathrm{C}$ и сопровождается внутримолекулярной дегидратацией с образованием связей $\mathrm{C}=\mathrm{O},-\mathrm{C}=\mathrm{C}-$. В нашем случае потеря массы в данный промежуток составила $\approx 3 \%$.

Интервал температур $240-400{ }^{\circ} \mathrm{C}$ соответствует третьей стадии карбонизации, в результате протекания реакций деполимеризации, декарбоксилирования, декарбонилирования и других образуются низкомолекулярные продукты распада. В этом интервале температур потеря массы сорбента составила $\approx 5 \%$, видимо, это связано с высоким выходом летучих смолистых веществ [8, 9].

К основным процессам четвертой стадии $\left(400-700{ }^{\circ} \mathrm{C}\right)$ относятся ароматизация с выделением водорода и конденсация фрагментов $\mathrm{C}_{4}$ в «углеродный полимер», в результате чего образуются графитоподобные слои. При термообработке рассматриваемого сорбента в данный отрезок температуры потеря массы составляет $\approx 17 \%$.

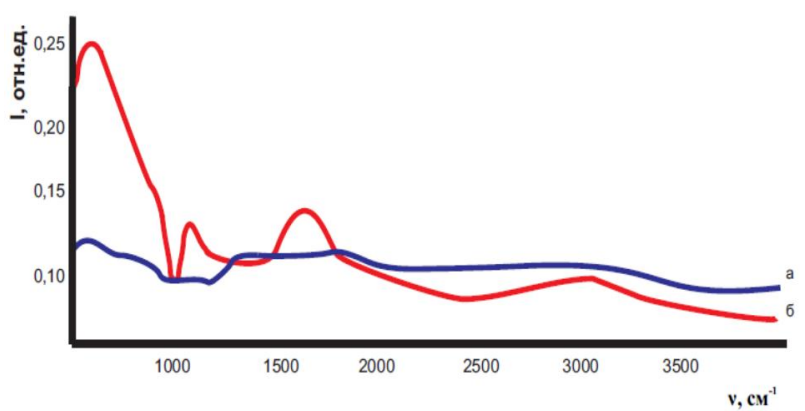

Рис. 1. ИК-спектр исходного материала (а), модифицированного карбонизированного сорбента (б)

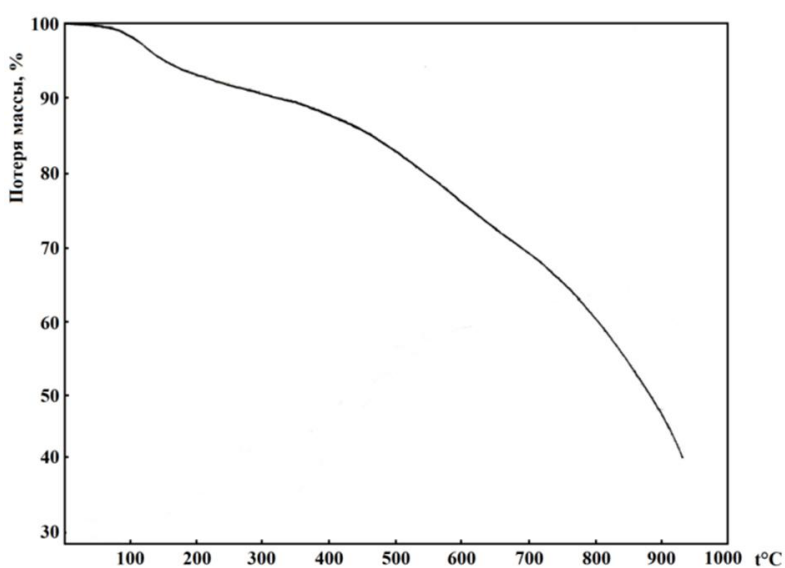

Рис. 2. Термограмма разложения сорбента после обработки его при $800{ }^{\circ} \mathrm{C}$ 
Необходимо предположить, что соединения фосфора являются термически нестабильными, и при повышении температуры карбонизации до $800{ }^{\circ} \mathrm{C}$ происходит удаление фосфорсодержащих соединений в виде летучих продуктов из образца, это в свою очередь может способствовать образованию более пористой структуры сорбента, тем самым повышая его сорбционную емкость.

Далее было проведено изучение сорбционных свойств сорбента по отношению к йоду, результаты приведены на рисунке 3.

Установлено, что наибольшей сорбционной емкостью по йоду обладает сорбент, прошедший термообработку при $800{ }^{\circ} \mathrm{C}$.

Исследования сорбционной емкости полученного сорбента по отношению к ионам $\mathrm{Cu}^{2+}$ были проведены в статических условиях.

Эксперименты по изучению сорбции в статическом условии проводили по методу математического планирования, по результатам которого было получено обобщенное уравнение Протодьяконова [6], описывающее влияние всех факторов ( $\mathrm{pH}$, продолжительность контакта сорбента с раствором, исходная концентрация сорбента):

$$
a=\frac{(1,176 p H+95,61) \cdot\left(1,92 C_{\mathrm{исx}}-9,43\right) \cdot(2,64 \ln \tau+91,92)}{\bar{a}^{2}} .
$$

Это уравнение представляет возможным прогнозирование сорбционной емкости изучаемого сорбента при варьировании вышеуказанных факторов.

Минимальное значение степени очистки $(78,21 \%)$ получено при $\mathrm{pH} 4$, исходной концентрации сорбата 25 мг/г, 30 мин контакта сорбента с раствором меди (II), максимальное значение степени (94,76\%) очистки достигнуто при условиях $\mathrm{pH} 8, \mathrm{C}_{\text {исх }}\left(\mathrm{Cu}^{2+}\right)=100$ мг/г, продолжительности контакта 480 мин.

Оптимальное значение $\mathrm{pH}=8$, видимо, объясняется тем, что при $\mathrm{pH} \geq 6,9$ медь сорбируется в виде иона $\mathrm{CuOH}^{+}$. Такие ионы ввиду меньшего заряда и большего радиуса, а также меньшей степени гидратации легче вступают в электростатические взаимодействия и ионный обмен по сравнению с ионом $\mathrm{Cu}^{2+}$.

На рисунке 4 представлены интегральные кинетические кривые сорбции при различных исходных концентрациях сорбента.

Как видно из рисунка 4, полное сорбционное равновесие достигается при всех температурах после 680 мин контакта.

По литературным данным [10] это свидетельствует о том, что несколько стадий определяют скорость сорбционного процесса. Для определения режима процесса сорбции (внешне- или внутридиффузионный) данные были обработаны по методу Бойда [11]. Далее была построена зависимость $-\ln (1-\mathrm{F})$ от $\tau$ (см. рис. 5).

В наших условиях фиксировался линейный участок во всем временном интервале при всех температурах. Выпуклый характер зависимости $\mathrm{F}-\tau^{1 / 2}$ (см. рис. 6) так же свидетельствует о том, что лимитирующей стадией сорбции меди (II) является внешняя диффузия.

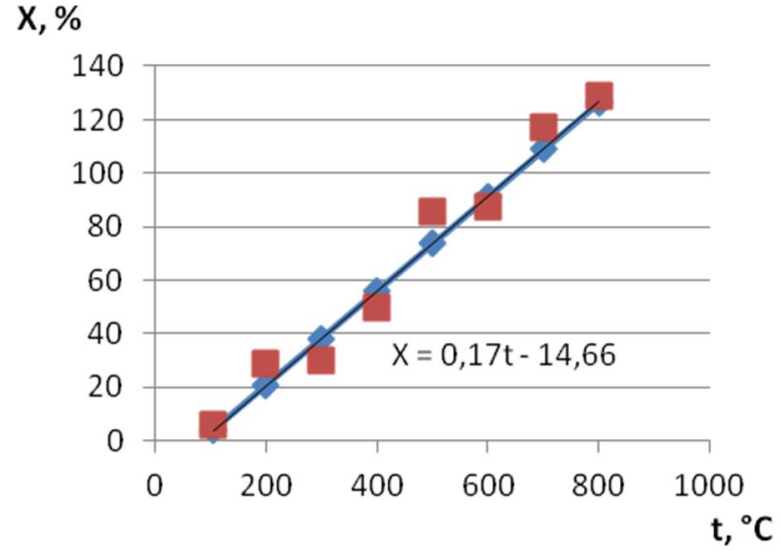

Рис. 3. Зависимость сорбционной емкости сорбента по отношению к йоду от температуры термообработки

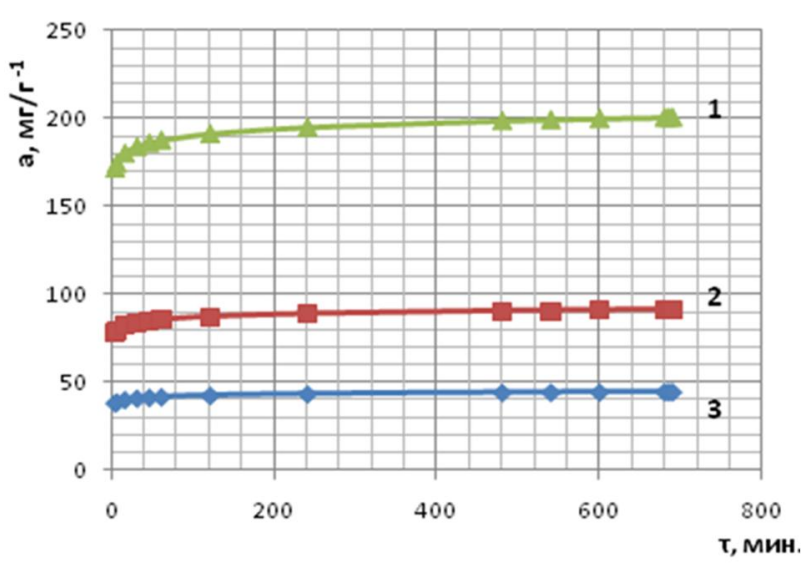

Рис. 4. Интегральные кинетические кривые сорбции меди (II) на древесно-карбонизированном сорбенте при исходной концентрации ионов $\mathrm{Cu}^{2+}$ : 1 - 100 мг/л, 2 - 50 мг/л, 3 - 25 мг/л, температуре $298 \mathrm{~K}, \mathrm{pH} 8$ 


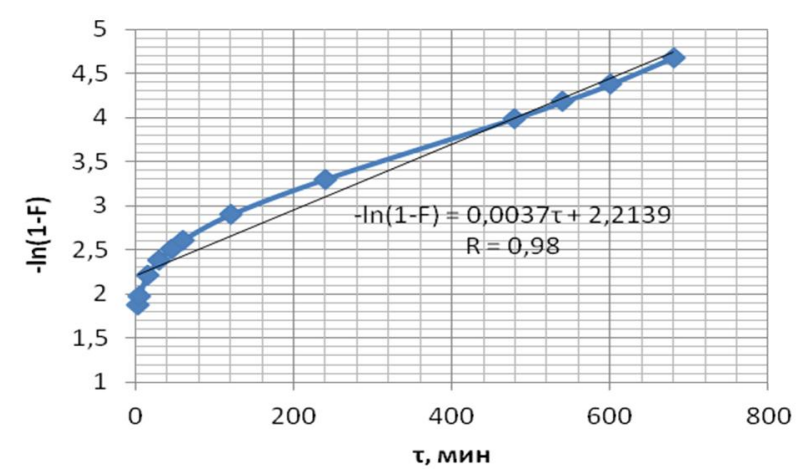

Рис. 5. Зависимость $-\ln (1-\mathrm{F})$ от $\tau$ для сорбции ионов меди (II), исходная концентрация ионов меди $\mathrm{Cu} 2+100$ мг/г, $\mathrm{pH} 8$

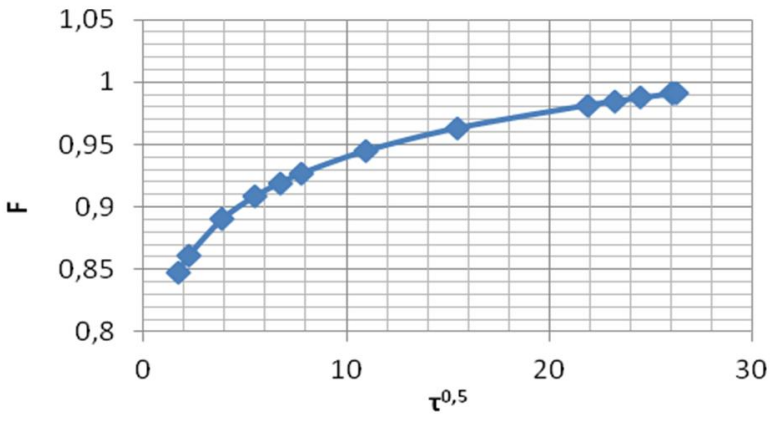

Рис. 6. Зависимость F от $\tau 1 / 2$ для сорбции ионов меди (II)

Таким образом, основным лимитирующим является внешнедиффузионный процесс. Модель Бойда основана на том, что стадия ионного обмена протекает практически мгновенно и не может контролировать общую скорость процесса. Для выявления вклада химической стадии в общую скорость процесса кинетические кривые сорбции были обработаны путем применения модели псевдопервого порядка. Параметры, рассчитанные на основании интегральных кинетических кривых с использованием кинетической модели псевдопервого порядка, представлены в таблице.

Из данных, представленных в таблице и рисунках 3-5, видно, что в данном случаем сорбцию ионов меди (II) наилучшим образом описывают моделью псевдопервого порядка. Следует отметить, что уравнение модели псевдопервого порядка идентично уравнению для пленочной диффузии. Однако в случае диффузии в пленке скорость процесса зависит от размера частиц сорбента и толщины пленки.

Уравнения моделей химической кинетики и константы скорости процесса сорбции, исходная концентрация ионов меди $\mathrm{Cu}^{2+} 100$ мг/г, $\mathrm{pH} 8,298 \mathrm{~K}$

\begin{tabular}{|c|c|c|c|}
\hline Модель, уравнение & $\mathrm{a}, \mathrm{M \Gamma} \cdot \Gamma^{-1}$ (эксп.) & a, мг· $\Gamma^{-1}$ (расч.), по модели & $\begin{array}{c}\text { Константа скорости } \\
\mathrm{k}_{1}, \text { мин }^{-1}\end{array}$ \\
\hline $\begin{array}{c}\text { Псевдо-первого порядка } \\
a_{t}=a_{e}\left(1-e^{-k_{1} \cdot t}\right)\end{array}$ & 202,00 & 203,77 & $\mathrm{k}_{1}=0,1097$ \\
\hline
\end{tabular}

\section{Bыводbl}

Исследованы структурные особенности продуктов, полученных в процессе карбонизации отходов хвойной древесины, модифицированной $\mathrm{H}_{3} \mathrm{PO}_{4}$ после водной обработки. Показано, что в процессе карбонизации образцов с добавками $\mathrm{H}_{3} \mathrm{PO}_{4}$ при температуре $800{ }^{\circ} \mathrm{C}$ образуется пористый материал с удельной поверхностью до $870 \mathrm{~m}^{2} /$ г. Установлено, что сорбционная емкость по йоду сорбента, карбонизированного при $800{ }^{\circ} \mathrm{C}$, составляет 128,68\%. Также показано, что полученные активные угли могут применяться при очистке вод от ионов меди (II). Кинетика этого процесса описывается моделью псевдопервого порядка, сорбции предшествует диффузия.

\section{Список литературы}

1. Решение V Всероссийской конференции «Новые достижения в химии и химической технологии растительного сырья»// Химия растительного сырья. 2012. №2. С. 205-206.

2. ГОСТ 16483.7-71. Древесина. Методы определения влажности.

3. ГОСТ 6382-2001. Топливо твердое минеральное. Методы определения выхода летучих веществ.

4. ГОСТ 6217-74. Уголь активный. Древесный дробленый. Технические условия.

5. Амерханова Ш.К., Уали А.С., Дюсенбаева А.К., Жаслан Р.К. Получение и исследование свойств сорбентов на основе модифицированной хвойной древесины // Проблемы теоретической и экспериментальной химии: тезисы докл. ХХІІІ Российской молодежной науч. конф. Екатеринбург, 2013. С. 67-68.

6. Малышев В.П. Математическое планирование металлургического и химического эксперимента. Алматы, 1977. $37 \mathrm{c}$.

7. Углеродные наностуктурированные материалы на основе растительного сырья / под ред. 3.А. Мансурова. Алматы, 2010. $301 \mathrm{c.}$

8. Кислицын А.Н. Пиролиз древесины: химизм, кинетика, продукты, новые процессы. М., 1990. 312 с. 
9. Дейнеко И.П. Химические превращения целлюлозы при пиролизе // Известия вузов. Лесной журнал. 2004. №4. C. 97-112.

10. Karaca S., Gürses A., Ejder M. Kinetic modeling of liquid-phase adsorption of phosphate on dolomite // J. Colloid Interf. Sci. 2004. Vol. 277, N1. Pp. 257-263.

11. Boyd G.E., Adamson A.W., Myers L.S. The exchange adsorption ofions fromaqueous solutions byorganic zeolites. II. Kinetics // J. Am. Chem. Soc. 1947. Vol. 69, N11. Pp. 2836-2848.

Поступило в редакииию 28 февраля 20142.

После переработки 18 мая 2014 г.

Amerkhanova Sh.K. , Uali A.S., Zhaslan R.K. PROPERTIES OF ACTIVATED CARBONS DERIVED FROM DRY CONES PINNUS SYLVÉSTRIS

E.A. Buketov Karaganda State University, Universitetskaia st., 28, Karaganda, 100028 (Kazakhstan),

e-mail: amerkhanova_sh@mail.ru

We have investigated the reception of activated carbons from waste softwood Pinus sylvestris by modifying the phosphoric acid followed by carbonization at $800{ }^{\circ} \mathrm{C}$ and high temperature steam treatment. The sorption properties of the material obtained with respect to copper ions (II). The structural features of the products obtained in the course of carbonization. It is shown that in the process of carbonization samples with additives $\mathrm{H}_{3} \mathrm{PO}_{4}$ at $800{ }^{\circ} \mathrm{C}$, a porous material with a specific surface of $870 \mathrm{~m}^{2} / \mathrm{g}$. It is found that the sorption capacity for iodine sorbent carbonized at $800^{\circ} \mathrm{C}$, is $128.68 \%$. Also shown is that the resulting active carbons can be used in the purification of water from a copper ion (II), the kinetics of this process model is described pseudo-first order precedes sorption diffusion.

Keywords: pine cones, phosphoric acid adsorption capacity of iodine, copper ions (II).

\section{References}

1. Khimiia rastitel'nogo syr'ia, 2012, no. 2, pp. 205-206. (in Russ.).

2. GOST 16483.7-71. Drevesina. Metody opredeleniia vlazhnosti. [State Standard 16483.7-71. Wood. Methods for determination of moisture content]. (in Russ.).

3. GOST 6382-2001. Toplivo tverdoe mineral'noe. Metody opredeleniia vykhoda letuchikh veshchestv. [State Standard 6382-2001. Solid mineral fuel. Methods for determining the release of volatile substances]. (in Russ.).

4. GOST 6217-74. Ugol' aktivnyi. Drevesnyi droblenyi. Tekhnicheskie usloviia. [State Standard 6217-74. Coal is active. Wood crushed. Technical conditions]. (in Russ.).

5. Amerkhanova Sh.K., Uali A.S., Diusenbaeva A.K., Zhaslan R.K. Problemy teoreticheskoi i eksperimental'noi khimii: tezisy dokl. XXIII Rossiiskoi molodezhnoi nauch. konf. [Problems of Theoretical and Experimental Chemistry: abstracts XXIII Russian Youth Scientific Conference]. Yekaterinburg, 2013, pp. 67-68. (in Russ.).

6. Malyshev V.P. Matematicheskoe planirovanie metallurgicheskogo i khimicheskogo eksperimenta. [Mathematical planning of metallurgical and chemical experiments.]. Almaty, 1977, 37 p. (in Russ.).

7. Uglerodnye nanostukturirovannye materialy na osnove rastitel'nogo syr'ia. [Carbon nanostukturirovannye materials based on vegetable raw materials]. Ed. Z.A. Mansurov. Almaty, 2010, 301 p. (in Russ.).

8. Kislitsyn A.N. Piroliz drevesiny: khimizm, kinetika, produkty, novye protsessy. [Pyrolysis of wood: chemistry, kinetics, products, new processes]. Moscow, 1990, 312 p. (in Russ.).

9. Deineko I.P. Izvestiia vuzov. Lesnoi zhurnal, 2004, no. 4, pp. 97-112. (in Russ.).

10. Karaca S., Gürses A., Ejder M. J. Colloid Interf. Sci., 2004, vol. 277, no. 1, pp. 257-263.

11. Boyd G.E., Adamson A.W., Myers L.S. J. Am. Chem. Soc., 1947, vol. 69, no. 11, pp. 2836-2848.

Received February 28, 2014

Revised May 18, 2014

\footnotetext{
* Corresponding author.
} 
